4 Hoenig HM, Rubenstein L.Z. Hospital-associated deconditioning and dysfunction. 7 Am Geriatr Soc 1991;39:220-2.

5 Bliss M. Medical implications of the sedentary posture. Care, Science and Practice 1990;8:104-8.

6 Petersen NC, Bittmann S. The epidemiology of pressure sores. Scand 7 Plast Reconstr Surg 1971;5:62-6.

Barbenel JC, Jordan MM, Nicol SM, Clark MO. Incidence of pressure sores in the greater Glasgow health board area. Lancet 1977;ii:548-50.

Nyquist R, Hawthorn PJ. The prevalence of pressure sores within an area health authority. $\mathrm{I} A d v$ Nurs 1987;12:183-7.

9 Warren MW. Care of the chronic aged sick. Lancet 1946;i:841-3.
10 Alexander NB, Schultz AB. Rising from a chair: effects of age and functional ability on performance biomechanics. 7 Gerontol 1991;46:M91-8.

1 Finlay OE, Bayles TB, Rosen C, Milling J. Effects of chair design, age and cognitive status on mobility. Age Ageing 1983;12:329-35.

12 Downton JH. Falls in the elderly. London: Edward Arnold, 1993.

13 Calder CJ, Kirby RL. Fatal wheelchair-related accidents in the United States. Am J Phys Med Rehabil 1990;69:184-90.

14 Guite HF, Bliss MR, Mainwaring-Burton RW, Thomas JM, Drury PL. Hypothesis: posture is one of the determinants of the circadian rhythm of urine flow and electrolyte excretion in elderly female patients. Age Ageing 1988;7:241-8.

\title{
Private health care: patients' beliefs and practice
}

\author{
People's views largely reflect who pays the premium
}

The past decade has witnessed considerable growth in the number of people with private health insurance in Britain. Given the existence of a well established tax based public system, why do some people subscribe privately, when do they use their insurance, and what value do they place on it? To answer these questions, Calnan and his colleagues conducted a postal survey in 1989 of 3060 men aged 35-55 living in the relatively affluent county of Kent. ${ }^{1}$ Of the 1688 $(55 \%)$ who responded, $29 \%$ had insurance. The survey data were supplemented by 60 in depth interviews. Three principal findings emerged: people with insurance are a heterogeneous group who need to be considered in terms of who pays their subscription; often their views of the NHS seem to contradict their behaviour; and the extent to which insurance confers greater autonomy and choice is often severely limited.

Subscribers fell into one of three equally sized groups based on who paid - the men themselves, their company, and both jointly. This distinction is important: people's reasons for subscribing, the use they made of their insurance, and the value they attached to it varied among the three groups. Individual subscribers tended to be dissatisfied with the NHS, though this was partly based on hearsay rather than experience. Being mostly self employed they wanted rapid treatment at a time of their choosing. Some also believed that they would receive more individualised treatment if they went privately. Having private insurance was consistent with their broader sociopolitical beliefs of minimising the role of the state, maximising individual responsibility, and supporting markets. Despite all these perceived advantages only about half of the men had used their insurance; this partly reflected their reluctance to cause their premium to rise in response to a claim. Overall they saw insurance as a necessity and a commodity like any other that influenced their material circumstances.

In contrast, company subscribers simply saw insurance as a perk or an enforced gift. Most would not consider paying for it themselves if their company stopped doing so. Although not committed to private health care, they were generally intent on "getting their money's worth," and there was no financial incentive to avoid claims (though this is changing as employers increasingly encourage subscribers to use the NHS). Far from seeing insurance as a status symbol, many company subscribers felt some embarrassment about having it. Finally, those with joint payment expressed somewhat similar views to the company subscribers but were subject to some of the financial incentives of the individual subscribers.

Subscribers' views of the NHS were often contradictory and confusing. Saunders and Harris suggested previously that this is inevitable, given that it is not possible to opt out of contributing to the cost of the NHS and therefore there is no point in railing against it. ${ }^{2}$ Calnan and his colleagues, however, found that subscribers held a more positive attitude towards the NHS. There was a general allegiance to its ideals, even among individual subscribers. Two theories had previously been suggested to explain this. One argued that subscribers who favoured markets welcomed the NHS as a competitor which could provide the best value for money for many aspects of health care. ${ }^{3}$ The other suggested that, quite correctly, subscribers recognised their own need for both a private and a public system. ${ }^{4}$ This view was borne out by the subscribers interviewed in this latest study. Private care was seen as a substitute for rather than a complement to the NHS. Subscribers' desire for the timely, convenient care available through insurance was tempered by concerns about its expense and the greater risk of being subjected to inappropriate interventions than would occur in the NHS (though the only two studies to have examined this suggest that such fears may be unfounded). ${ }^{56}$

If the obvious limitations of the services available privately are set aside, market theory suggests that one advantage of insurance would be greater autonomy and choice for subscribers. This seems to have been greatly overestimated. Firstly, subscribers limit their demands because they are uncertain about the extent of their coverage; their perception of the remit of the private sector is unrealistically narrow; they fear the financial repercussions of claiming; and many company subscribers are opposed in principle to private medicine. Secondly, when they do seek to use their insurance their general practitioner may advise against doing so. Whether general practitioners will continue to act as restrictive gatekeepers as fundholding in the NHS spreads is unclear. Overall, subscribers lack the necessary information to empower them to be enterprising and critical consumers. Indeed, the only evidence that insurance can lead to a more egalitarian relationship comes from observational studies of doctor-patient interactions. ${ }^{78}$ Thus, the notion of increased consumer sovereignty in the private sector seems a myth.

While this new study sheds some more light on the private sector, we remain woefully ignorant about many aspects of its workings. This reflects partly a degree of secretiveness on the part of the private sector and partly a reluctance by the research community to take an interest in it. Given the current trend towards a more mixed economy of health care, more cooperation for research across the public:private interface is needed.

Division of Health Services Research,

NICK BLACK Visiting scholar

Health Institute,

New England Medical Center,

Boston, MA 02111, USA 
1 Calnan M, Cant S, Gabe J. Going privale. Why people pay for their health care. Buckingham: Open University Press, 1993

2 Saunders P, Harris C. Popular attitudes to social welfare services. London: Social Affairs University, 1989.

3 Taylor-Gooby P. Welfare attitudes: cleavage, consensus and citizenship. fournal of Social Affairs 1987;3:199-221.

4 Busfield J. Sectoral divisions in consumption: the case of medical care. Sociology 1990;24: $77-98$.
5 Scott EA, Black NA. Appropriateness of cholecystectomy: the public and private sectors compared. Ann R Coll Surg Eng 1992;74(suppl):97-101.

6 Black N, Petticrew M, McPherson K. Comparison of NHS and private patients undergoing elective transurethral resection of the prostate for benign prostatic hypertrophy. Quality in Health Care 1993;2:11-6.

7 Strong PM. The ceremonial order of the clinic. London: Routledge and Kegan Paul, 1979.

8 Silverman D. Going private: ceremonial forms in a private oncology clinic. Sociology 1984;18: $191-204$.

\section{Whither health care in South Africa?}

\section{Expanding primary health care is the only way forward}

Forty years of apartheid has allowed the development of sophisticated medical care for its supporters while the basic health needs of the disenfranchised majority have been deliberately neglected. As a result the health care services to the public sector in South Africa today are fragmented, underfunded, and both financially and geographically inaccessible to many communities, especially in periurban and rural areas.

In contrast, an expensive and overserviced private health care sector supplies a high level of care to one fifth of South Africans who form the elite, affluent sections of the community. Ironically, the provision of private health care is partially funded by the general public while medical schools train doctors suited best for private practice or export. Academic isolation has further damaged the standard of specialist care offered by the public service.

Recently, genuine efforts have been made by the government to rectify this. A very distorted public health service, however, will be inherited by a new, democratically elected government.

While these weaknesses bedevil the provision of health care for all, there remain well trained and highly motivated doctors and nurses and other health care workers in the country committed to a new era in health care. Seven medical schools, regional and district hospitals, and a good transport and communications infrastructure are already in place. What is awaited is an urgent restructuring of health care services. To plan and implement a health service that will address the deficiencies of the past presents an enormous challenge to both health care workers and the public.

What is needed is an effective and equitable health service. It would be based on an integrated, regionalised system that draws in all the current state, non-governmental, and private sectors. The most urgent need is for primary health care to be developed in all parts of the country. It should be linked to a comprehensive system of community health services and regional hospitals with an upward chain of referral and a downward chain of support. Given the limited resources available, the optimal use of staff and facilities is vital. Community clinics staffed by nurses are needed, with particular attention given to maternal and child health. To be acceptable to the community, primary care will have to be backed up by facilities for secondary care.

Many people view the availability of essential health care for all as a human right, which should be incorporated into a new constitution. A national health service, with a strong emphasis on primary care services aimed at redressing the inequalities of the past, is widely supported, and many progressive health planners favour adopting the World Health Organisation's concept of the district as the basic building block of such a service. Working models of such districts would need to be established to allow rational decisions to be made about the pattern of future services. Final details of funding and planning details will have to be reached by consensus as priorities and needs may vary widely between local communities.

Providing tertiary care is more problematical, given its expense and its need for many highly trained personnel. As a result, providing it to the standard demanded by the privileged minority in the past may not be possible. In the spirit of a free enterprise economy a parallel system of private health care should remain available for those who can afford it, but all public funding for private health care will have to be withdrawn.

Health and social and economic development are interdependent. Together with the development of a national health service, attention must be given to adequate housing, basic sanitation, an adequate supply of safe water, the promotion of public health, employment through sustained economic growth, improved nutrition, education, agricultural development, electrification, and respect for the environment.

The academic centres need to be reoriented to serve the needs of the whole population, entailing changes in service, teaching, and research. Medical schools and nursing colleges will have to equip their graduates with knowledge, attitudes, and skills needed for implementing a new health policy. The role of the nurse and possibly the traditional healer will expand, demanding many painful changes to current training programmes. Innovative educational methods will have to be devised to train the many health care workers who are presently providing services under difficult circumstances.

The limiting factors will be money and having too few health administrators who are capable of creating and maintaining a new system of health care. But the problems facing health care in South Africa are not insurmountable, and the country has the capacity to provide appropriate, acceptable, affordable, and equitable health care for all its people.

DAVID WOODS Associate professor DAVID POWER Professor

Department of Paediatrics and Child Health,

University of Cape Town,

Private Bag,

Rondebosch 7700

South Africa

\section{Correction}

\section{Gene therapy begins}

We regret that there were two errors in the editorial by Kay Davies and Bob Williamson (19 June, pp 1625-6). The first, for which the authors are responsible, is that most retroviral vectors are not derived from mouse mammary tumour virus (which has only rarely been suggested as a vector) but from another retrovirus, Moloney murine leukaemia virus. The second error was introduced during editing-the low density lipoprotein receptor controls the concentration of circulating cholesterol and not blood glucose. 